\title{
Role of depression and its associating factors in indoor orthopaedic patients
}

\author{
Ravikant Jain', Rahul Rishi' ${ }^{2}$, Balkishan Sharma ${ }^{3}$, Vivek Kiyawat ${ }^{2}$

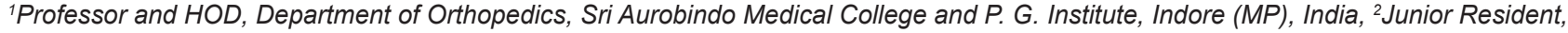 \\ Department of Orthopedics, Sri Aurobindo Medical College and P. G. Institute, Indore (MP), India, ${ }^{3}$ Associate Professor (Biostatistics), \\ Department of Community Medicine, Sri Aurobindo Medical College and P. G. Institute, Indore (M. P.), India
}

\section{A B S TR A C T}

Background and Objectives: Depression has acknowledged and well documented, is common among orthopaedic inpatients may be associated with functional outcomes. Authors aimed to investigate the role, prevalence and associating factors of depression disorder in orthopaedic inpatients. Materials and Methods: A cross-sectional study is designed among patients that admitted at Sri Aurobindo Medical College and P. G. Institute, Indore. Four hundred twenty six orthopedic patients were recruited for study. The demographic and clinical measurements were recorded. Levels of depression were assessed by using Zung's depression scale. Results: Depressive disorder was identified in $87.6 \%$ indoor patients significantly $(p<0.001)$ influenced female more than male. The mean depression score in female (67.37 \pm 11.75$)$ was significantly higher than male $(62.29 \pm 12.20)$. The prevalence of extreme/major depression in female $(46.6 \%)$ was higher as compared to male $(25.7 \%)$. Type of trauma was found significantly $(p<0.05)$ associated with depressive disorder. $38.1 \%$ male with traumatic condition and $20.0 \%$ with non-traumatic condition had moderate depression in comparison to $31.4 \%$ and $13.6 \%$ female. Depressive disorder was found significantly associated with sex $(p<0.001)$, socio-economic status $(p<0.001)$, length of ortho-illness $(p<0.001)$, length of stay in hospital $(p<0.001)$, exercise/yoga $(p<0.05)$ and type of injury $(p<0.05)$. Conclusions: Higher incidence of depressive disorder recorded in female. Prevention and treatment require more clinical and research attention to reduce the public health burden of depression. The study suggested that higher depressive disorder does occur in indoor orthopaedic patients that associated with various functional outcomes. This study supports the view of depressive disorder was disabling factor in better functional recovery and frequent in female after orthopedic trauma.

Key words: Depression, Orthopaedic trauma, Injury, Psychosocial, Major depressive disorder
Access this article online

Website:

http://nepjol.info/index.php/AJMS

DOI: 10.3126/ajms.v6i6.12478

\section{INTRODUCTION}

Depression is a state of low mood and aversion to activity that can affect a person's thoughts, behavior, feelings and sense of well-being. ${ }^{1}$ Depression has received a lot of attention in the media and is far more widely accepted today than it has ever been in the past. Anxiety is usually a precursor to depression, can reduce the efficiency of healthy individuals. ${ }^{2}$ The combination of a physical illness and depressive disorder is a particularly potent cause of disability. ${ }^{3}$ Depressive disorder is projected to be the leading cause of disability in the developing world by
2020 and leads to greatly increased healthcare costs even after excluding direct mental healthcare expenses. ${ }^{4}$ An estimated 340 million people across the world have major depressive disorder at any given time. ${ }^{5}$ Major depressive disorder (MDD) is also known as clinical depression or major depression is a mental disorder characterized by a pervasive and persistent low mood that is accompanied by low self-esteem and by a loss of interest or pleasure in normally enjoyable activities. Increased rates of depression in high-income countries have been reported in general trauma patients ${ }^{6-8}$ and in one US orthopaedic population the rate of depression was $45 \% .{ }^{9}$ Depressed people can feel 
sad, anxious, empty, hopeless, worried, helpless, worthless, guilty, irritable, hurt, or restless. Prevalence of psychological disorder following physical trauma in a variety of settings was $23 \%$ to $41 \%$. $^{10-11}$

Major depression significantly affects a patient's outcome of disease, general health and impacted on important functioning responsible for recovery after orthopedic trauma. Different sub-divisions of depression have different treatment approaches. Depression may also coexist with attention-deficit hyperactivity disorder (ADHD), complicating the diagnosis and treatment of both. ${ }^{12}$ Posttraumatic stress disorder (PTSD) is also common after surgery, particularly after traumatic injuries and other issues in surgical patients. ${ }^{13-14}$ More than 40 percent of people with PTSD also had depression at one-month and four-month intervals after the traumatic event. ${ }^{15}$ Since depression is common and ${ }^{16}$ one might expect a high rate of depression associated with physical injury and musculoskeletal issues presenting at orthopaedic clinics and ${ }^{17}$ females were more likely to become depressed than males.

Contextual factors play an important role in determining the level of disability associated with a health condition. ${ }^{18}$ Other than access to treatment, patient and carers attitude may affect the relative level of disability associated with different health conditions in the orthopaedic patients. There is some evidence that fish oil supplements containing high levels of eicosapentaenoic acid (EPA) to docosahexaenoic acid (DHA) may be effective in major depression. ${ }^{19}$ High rates of depression have been documented in patients with severe lower-extremity injury. ${ }^{20}$ However, patients with less severe injuries have not been associated with regard to their rates of depression to our knowledge. The relationship between traumas in indoor orthopaedics and depression is not clear. In addition, little is known about the association between depression and demographics during hospitalization. A weak association of anxiety/depression with an increase in heart rate was confirmed the effect of anxiety and depression on decrease in blood pressure. ${ }^{21}$

The understanding of the nature and causes of depression has evolved over the centuries has left many aspects of depression as the subject of discussion and research. The authors hypothesized that depression is associated with various demographical and clinical settings during hospitalization among indoor orthopaedic patients. Henceforth, the authors aimed to utilize the depressive disorder in clinical condition to identify the role and prevalence with demographic and other associating factors.

\section{MATERIALS AND METHODS}

A cross-sectional study is designed among indoor orthopaedic traumatic and non-traumatic patients after obtaining ethical approval that admitted at Sri Aurobindo Medical College and P. G. Institute, Indore during November 2013 to May 2014. Four hundred twenty six orthopedic patients were recruited during specified period selected as subjects according to inclusion criteria. Prior consent of patients for the publication of the clinical details and others has taken into account. The anthropometric and demographic measurements were recorded. Those patients were also eliminated from the study that had previously been diagnosed with depression and were already receiving treatment for this condition. After explaining the purpose of the study a questionnaire was provided and was asked to answer (fill up) the questions in prescribed format so as to assess their depression level.

Zung's scale ${ }^{22}$ was selected for assessment and scoring of depression level. The Likert Scale Format is being used in questionnaire that consisted of twenty questions. Each question has answer score from 1 to 4 . The option for each question is (a) None or a little of the time (b) Some of the time (c) Good part of the time and (d) Most or all of the time. The raw score is converted to 100 point scale (SDS Raw Index). SDS Raw Index $=($ Raw Score $/ 80$ total points $) \times 100$ and SDS Index $=$ SDS Raw Index $\times 1.25$. Subject who received SDS Index point $<50$ was treated as Normal, 51-59.9 was noted as Mild Depression, 60-69.9 was treated as Moderate or Marked Major Depression and $>70$ was considered as Severe or Extreme Major Depression. The demographic and clinical measurements were recorded and associations between various study parameters with depression level were evaluated.

\section{Statistical analysis}

The Data were entered into the computer database. The empirical findings had been synthesized that further analyzed by using statistical software SPSS Version 17.0 in order to observe the descriptive statistics like mean and standard deviation among different study variables. Prevalence of an outcome variable along with 95\% confidence interval was calculated. Both, descriptive and inferential statistics were used to depict the features and characteristics of the data. Continuous variables are expressed as mean \pm standard deviation (or range). Non-continuous variables are expressed as number of occurrences and percentage.

The Chi-square test was carried out to identify the association of different demographic and other variables with depression. Z-test was used to compare the mean values of study variable among sex in relation to 
depression. The Zung's self-rating depression scale ${ }^{22}$ was analyzed by categorization of the three levels (Mild, Moderate or Marked Major and Severe or Extreme Major Depression) of depression as presence of depression. The probability value $\mathrm{p} \leq 0.05$ was considered as significant, $\mathrm{p} \leq 0.01$ and $\mathrm{p} \leq 0.001$ were considered as strongly/highly significant.

\section{RESULTS}

The age of male and female indoor orthopedic patients were identified in the ranges from 15 to 74 and 16 to 81 years respectively.

Table 1 depictes the features and characteristic of the selected indoor orthopedic patients. Age of male ( $34.17 \pm 14.42$ year) and female patient was (46.83 \pm 17.67 year) found significantly differ $(\mathrm{p}<0.001)$. Body mass index in male and female $\left(23.81 \pm 6.68\right.$ and $\left.22.81 \pm 6.80 \mathrm{~kg} / \mathrm{m}^{2}\right)$ and length of ortho-illness (69.95 \pm 145.99 and $63.28 \pm 102.35)$ was not significantly differ $(\mathrm{p}>0.05)$. The length of stay in hospital was observed significantly differ $(p<0.05)$ for male and female. The Socio-economic status of subjects was found low as most of the male $(45.7 \%)$ and female (60.2) were belong to low status but $71.4 \%$ male and $64.1 \%$ male and female were surviving in urban area. 88.6\% male and $91.2 \%$ female were reported more frequently traumatic while $58.3 \%$ and $53.8 \%$ male and female respectively exercising and meditating. Addiction was observed in $34.3 \%$ male and $8.4 \%$ in female (Table-1).

Table 2 highlighted that the prevalence of depression in total male was $82.3 \%$ as compared to $91.2 \%$ in total female. The prevalence of extreme/major depression in total female $(46.6 \%)$ was higher as compared to total male $(25.7 \%)$. Type of trauma was found significantly $(p<0.05)$ associated with symptoms of depressive disorder among male and female indoor patients. $38.1 \%$ male with traumatic condition and $20.0 \%$ with non-traumatic condition had moderate depression in comparison to $31.4 \%$ and $13.6 \%$ female. Female was identified with higher depression level as compared to male because $45.0 \%$ female with traumatic condition and $63.6 \%$ with non-traumatic condition determined with extreme/major depression in comparison to $23.2 \%$ and $45.0 \%$ male. A maximum of $18.7 \%$ patients were identified normal after hospitalization.

Depressive disorder was found significantly associated with different variables in indoor orthopedic patients presented in table 3. Sex was found to be the strong significant $(\mathrm{p}<0.001)$ factor that influences highly the level of depression as $72.2 \%$ and $54.3 \%$ female respectively observed with severe and moderated depressive disorder. Socio-economic status and length of length ortho illness was highlighted with strong association $(\mathrm{p}<0.001)$ with depression.

\begin{tabular}{|c|c|c|c|c|c|}
\hline \multirow[t]{2}{*}{ Parameter } & \multicolumn{2}{|c|}{ Male $(n=175)$} & \multicolumn{2}{|c|}{ Female $(n=251)$} & \multirow[t]{2}{*}{ Significance } \\
\hline & Mean or proportion & SD & Mean or proportion & SD & \\
\hline \multicolumn{6}{|l|}{ Continuous } \\
\hline Age (year) & 34.17 & \pm 14.42 & 46.83 & \pm 17.67 & $p<0.001^{\#}$ \\
\hline Weight (kilogram) & 60.27 & \pm 12.34 & 56.28 & \pm 12.59 & NA \\
\hline Height (centimeter) & 160.23 & \pm 12.49 & 158.42 & \pm 11.36 & \\
\hline Body mass index $\left(\mathrm{kg} / \mathrm{m}^{2}\right)$ & 23.81 & \pm 6.68 & 22.81 & \pm 6.80 & $p>0.05^{\otimes}$ \\
\hline Ortho illness (days) & 69.95 & \pm 145.99 & 63.28 & \pm 102.35 & $p>0.05^{\otimes}$ \\
\hline Stay in hospital (days) & 18.06 & \pm 16.88 & 21.68 & \pm 18.98 & $p<0.05^{*}$ \\
\hline \multicolumn{6}{|l|}{ Non-continuous } \\
\hline \multicolumn{6}{|l|}{ Socio-economic status } \\
\hline Low & 45.7 & - & 60.2 & - & NA \\
\hline Medium & 41.7 & - & 27.1 & - & \\
\hline High & 12.6 & - & 12.7 & - & \\
\hline \multicolumn{6}{|l|}{ Area of residence } \\
\hline Rural & 28.6 & - & 35.9 & - & NA \\
\hline Urban & 71.4 & - & 64.1 & - & \\
\hline \multicolumn{6}{|l|}{ Type } \\
\hline Traumatic & 88.6 & - & 91.2 & - & NA \\
\hline Non-Traumatic & 11.4 & - & 8.8 & - & \\
\hline \multicolumn{6}{|l|}{ Exercise/Yoga } \\
\hline Yes & 58.3 & - & 53.8 & - & NA \\
\hline No & 41.7 & - & 46.2 & - & \\
\hline \multicolumn{6}{|l|}{ Addiction } \\
\hline Yes & 34.3 & - & 8.4 & - & NA \\
\hline No & 65.7 & - & 91.6 & - & \\
\hline
\end{tabular}

${ }^{\#}$ Mean difference between groups is strongly significant at the 0.001 level of significance. ${ }^{\otimes}$ Mean difference between groups is significant at the 0.05 level of significance. ${ }^{*}$ Mean difference is not significant at the 0.05 level of significance. [Degrees of freedom is 424]. NA: Not Applicable 


\begin{tabular}{|c|c|c|c|c|c|c|}
\hline \multirow{2}{*}{$\begin{array}{l}\text { Level of depression SDS } \\
\text { index }\end{array}$} & \multicolumn{2}{|c|}{ Traumatic } & \multicolumn{2}{|c|}{ Non Traumatic } & \multicolumn{2}{|c|}{ Total } \\
\hline & $\begin{array}{c}\text { Male } \\
(n=155)\end{array}$ & $\begin{array}{l}\text { Female } \\
(n=229)\end{array}$ & $\begin{array}{c}\text { Male } \\
(n=20)\end{array}$ & $\begin{array}{c}\text { Female } \\
(n=22)\end{array}$ & $\begin{array}{c}\text { Male } \\
(n=175)\end{array}$ & $\begin{array}{l}\text { Female } \\
(n=251)\end{array}$ \\
\hline$<50$ (normal) & $29(18.7)$ & $21(9.2)$ & $2(10.0)$ & $1(4.5)$ & $31(17.7)$ & $22(8.8)$ \\
\hline $51-59.9$ (mild) & $31(20.0)$ & $33(14.4)$ & $5(25.0)$ & $4(18.2)$ & $36(20.6)$ & $37(14.7)$ \\
\hline 60-69.9 (moderate) & $59(38.1)$ & $72(31.4)$ & $4(20.0)$ & $3(13.6)$ & $63(36.0)$ & $75(29.6)$ \\
\hline$\geq 70$ (severe or extreme major) & $36(23.2)$ & $103(45.0)$ & $9(45.0)$ & $14(63.6)$ & $45(25.7)$ & $117(46.6)$ \\
\hline
\end{tabular}

The association is significant at the 0.05 level of significance. The figure in parenthesis () denotes the corresponding percentage

\begin{tabular}{|c|c|c|c|c|c|}
\hline \multirow[t]{2}{*}{ Characteristic } & \multicolumn{4}{|c|}{ Depression level } & \multirow{2}{*}{$\begin{array}{c}\left(\chi^{2}\right) \\
\text { p-value }\end{array}$} \\
\hline & $<50$ normal & $<60$ mild & $<70$ moderate & $>70$ severe & \\
\hline \multicolumn{6}{|l|}{ Sex } \\
\hline Male & $31(58.5)$ & $36(49.3)$ & $63(45.7)$ & $45(27.8)$ & $(21.78)$ \\
\hline Female & $22(41.5)$ & $37(50.7)$ & $75(54.3)$ & $117(72.2)$ & $\mathrm{p}<0.001^{\#}$ \\
\hline \multicolumn{6}{|c|}{ Socio-economic status } \\
\hline Low & $21(39.6)$ & $44(60.3)$ & $72(52.2)$ & $94(58.0)$ & (14.98) \\
\hline Medium & $21(39.6)$ & $24(32.9)$ & $41(29.7)$ & $55(34.0)$ & $p<0.02^{*}$ \\
\hline High & $11(20.8)$ & $5(6.8)$ & $25(18.1)$ & $13(8.0)$ & \\
\hline \multicolumn{6}{|c|}{ Ortho Illness (weeks) } \\
\hline $0-6$ & $48(90.6)$ & $52(71.2)$ & $95(68.8)$ & $52(32.1)$ & $(82.19)$ \\
\hline $7-12$ & $4(7.5)$ & $15(20.5)$ & $26(18.8)$ & $60(37.0)$ & $\mathrm{p}<0.001^{\#}$ \\
\hline $13-18$ & $0(0.0)$ & $2(2.7)$ & $7(5.1)$ & $19(11.7)$ & \\
\hline$>18$ & $1(1.9)$ & $4(5.5)$ & $10(7.2)$ & 31 (19.1) & \\
\hline \multicolumn{6}{|c|}{ Stay in Hospital (weeks) } \\
\hline $0-4$ & $52(98.1)$ & $70(95.9)$ & $121(87.7)$ & $74(45.7)$ & $(118.96)$ \\
\hline $5-8$ & $1(1.9)$ & $3(4.1)$ & $15(10.9)$ & $70(43.2)$ & $\mathrm{p}<0.001^{\#}$ \\
\hline $9-12$ & $0(0.0)$ & $0(0.0)$ & $0(0.0)$ & $12(7.4)$ & \\
\hline$>12$ & $0(0.0)$ & $0(0.0)$ & $2(1.4)$ & $6(3.7)$ & \\
\hline \multicolumn{6}{|l|}{ Exercise/Yoga } \\
\hline Yes & 38 (71.7) & 35 (47.9) & 72 (52.2) & $92(56.8)$ & $(8.05)$ \\
\hline No & $15(28.3)$ & $38(52.1)$ & $66(47.8)$ & $70(43.2)$ & $p<0.05^{*}$ \\
\hline \multicolumn{6}{|l|}{ Addiction } \\
\hline Yes & $14(26.4)$ & $17(23.3)$ & $28(20.3)$ & $22(13.6)$ & $(6.00)$ \\
\hline No & 39 (73.6) & $56(76.7)$ & $110(79.7)$ & $140(86.4)$ & $p>0.05^{\otimes}$ \\
\hline \multicolumn{6}{|l|}{ Type of Injury } \\
\hline Major & $34(64.2)$ & $51(69.9)$ & $104(75.4)$ & 97 (59.9) & $(8.56)$ \\
\hline Minor & $19(35.8)$ & $22(30.1)$ & $34(24.6)$ & $65(40.1)$ & $p<0.05^{*}$ \\
\hline
\end{tabular}

The length of stay of subjects in hospital was the strong significant factor $(\mathrm{p}<0.001)$ impacted the level of depression as most of the subjects $(87.7 \%)$ who stayed 0 to 4 weeks observed with moderated depression while $43.2 \%$ subjects found with severe depression stayed 5 to 8 weeks. $3.7 \%$ subjects stayed more than twelve weeks obtained with severe depression. Exercise/Yoga and type of injury were also influencing the depressive disorder found significantly associated $(p<0.05)$ with different levels of depression but addiction wasn't impacted ( $\mathrm{p}>0.05)$ significantly.

Table 4 reported that the depressive disorder was identified as the most significant factor $(p<0.001)$ influencing female orthopedic indoor patients more as compared to male with a mean difference of 5.08 score points. The mean depression score in female (67.37 \pm 11.75$)$ was significantly higher as compared to male (62.29 \pm 12.20$)$.
The mean length of stay of female indoor patients was $21.68 \pm 18.98$ days significantly more in hospital in comparison to male was $18.06 \pm 16.88$ days but didn't influence the length of ortho-illness was $69.95 \pm 145.99$ days for male and $63.28 \pm 102.35$ days for female. The mean difference for length of ortho-illness for male and female was 6.67 days wasn't significantly different $(p>0.05)$ but mean length of hospitalization was 3.62 days was significantly different $(\mathrm{p}<0.05)$.

\section{DISCUSSION}

This article offers an introduction to the understanding of depressive disorder and its associating factors affecting the rehabilitation and healing during orthopedic traumas that impacted adversely on condition of health. The prevalence 


\begin{tabular}{|c|c|c|c|c|c|c|c|}
\hline \multirow[t]{2}{*}{ Parameter } & \multirow[t]{2}{*}{ Sex } & \multirow[t]{2}{*}{ Mean } & \multirow[t]{2}{*}{ Std. Dev. } & \multicolumn{2}{|c|}{$95 \% \mathrm{Cl}$ of Diff } & \multirow[t]{2}{*}{ p-value } & \multirow[t]{2}{*}{ LOS } \\
\hline & & & & LB & UB & & \\
\hline \multirow[t]{2}{*}{ Depression score (SDS index) } & Male & 62.29 & 12.20 & 2.77 & 7.39 & 4.32 & $p<0.001^{\#}$ \\
\hline & Female & 67.37 & 11.75 & & & & \\
\hline \multirow[t]{2}{*}{ Ortho IIIness (days) } & Male & 69.95 & 145.99 & -16.97 & 30.32 & 0.56 & $p>0.05^{\otimes}$ \\
\hline & Female & 63.28 & 102.35 & & & & \\
\hline \multirow[t]{2}{*}{ Stay in Hospital (days) } & Male & 18.06 & 16.88 & 0.10 & 7.13 & 2.02 & $p<0.05^{*}$ \\
\hline & Female & 21.68 & 18.98 & & & & \\
\hline
\end{tabular}

"Mean difference between groups is strongly significant at the 0.001 level of significance. *Mean difference between groups is significant at the 0.05 level of significance. ${ }^{\otimes}$ Mean difference is not significant at the 0.05 level of significance. [CI-Confidence Interval; Diff-Difference of mean; Degrees of freedom is 424]

of depression in female was (91.2\%) higher as compared to $(82.3 \%)$ male. Depressive disorder was identified as the most significant factor $(\mathrm{p}<0.001)$ influencing female orthopedic indoor patients more as compared to male which is in agreement with Sherina MS et al. (2006) $)^{23}$ who found that the prevalence of depression was also significantly higher among the females $(65.1 \%)$ compared to the males $(46.1 \%)$ and Moussavi $\mathrm{S}$ et al. $(2007)^{3}$ also found that the disabling nature of depression was common chronic conditions in the community.

Type of trauma was found significantly $(\mathrm{p}<0.05)$ associated with symptoms of depressive disorder among male and female indoor patients. $38.1 \%$ male with traumatic condition and $20.0 \%$ with non-traumatic condition had moderate depression in comparison to $31.4 \%$ and $13.6 \%$ female which is correlated with Holbrook TL et al. $(1998,1999)^{7,10}$, showed that post-injury depression, posttraumatic stress disorder (PTSD) are significantly associated with 6-month, 12-month and 18-month quality of well-being outcome.

The prevalence of extreme/major depression in total female $(46.6 \%)$ was higher as compared to total male (25.7\%) which is in agreement with Nickinson RS et al. $(2009)^{17}$ who reported that females were more likely to become depressed than males while Crichlow RJ et al. (2006) $)^{9}$ observed that the prevalence of clinically relevant depression approached $45 \%$ in a diverse cohort of orthopaedic trauma patients. Socio-economic status and ortho illness was highlighted with strong association $(p<0.001)$ with depression. Comorbidity was associated with greater symptom severity and lower levels of functioning. Shalev AY et al. $(1998)^{15}$ observed that major depression and PTSD are independent sequelae of traumatic events, have similar prognoses, and interact to increase distress and dysfunction. Prior depression was associated with a higher prevalence of major depression and with more reported symptoms while depressive disorder appears to be very common in orthopaedic outpatients and both social circumstances and nature of bone pathology are associated with such depression reported by Husain et al. (2010). ${ }^{24}$ Health-related phobias are common but often unknown to the physician, in part because patients are reluctant to report phobias observed by Levenson JL. ${ }^{25}$

High prevalence of depressive disorders in the general population, it is unsurprising that a high percentage of patients undergoing surgery are taking antidepressants. Sherina MS et al. (2006) ${ }^{23}$ found that age, sex, ethnicity and functional disabilities were significantly associated with depression. Depression is a common but serious illness, and most that experience it need treatment to get better. The length of stay of subjects in hospital was the strong significant factor $(p<0.001)$ impacted the level of depression $3.7 \%$ subjects stayed more than twelve weeks obtained with severe depression which is corroborated with recent research in which authors Nota SP et al. $(2014)^{26}$ highlighted that a moderate correlations between symptoms of depression and symptoms of post-traumatic stress disorder at enrolment and magnitude of disability 5-8 months after trauma.

Exercise/Yoga and type of injury were also influencing the depressive disorder found significantly associated $(p<0.05)$ with different levels of depression. Similar findings reported by Iolascon $G$ et al. (2011) ${ }^{27}$ who evidenced that patients who undergo surgery frequently experience depression that can worsening functional outcome. An early detection and an adequate intervention based on psychological support and pharmacological treatment can give good results. In a study conducted by Gureje $O(2008)^{28}$ found that the disability associated with major depressive disorder is far in excess of that associated with some common chronic and medical conditions among elderly Nigerians.

The depressive disorder was identified as the most significant factor $(\mathrm{p}<0.001)$ influencing female orthopedic indoor patients more as compared to male. In an academic medical research Sharma BK et al. (2011) ${ }^{29}$ reported that SDS Index of stress was more in girls as compared to boys. The length of mean stay of female indoor patients was significantly more in hospital but didn't influence the length of ortho-illness. During a research investigator Holmes J and House A (2000) ${ }^{30}$ showed that the length of hospital stay for the whole sample ranged from three to 190 days 
while the effect of psychiatric illness on length of stay is shown significant with the presence of dementia, delirium and depression each independently decreased the relative risk of being discharged sooner.

Several studies have documented the considerable burden associated with depression. There is clearly a need to focus on alleviating these problems as part of the rehabilitation process reported by Ponsford J et al. (2008). ${ }^{31}$ The research has shown that the prevalence of depression is directly associated to the length of stay in the rehabilitation ward thus periodic depression screenings of patients in the wards would be beneficial. Although, the recognition of depressive disorder followed by significant intervention can improve the orthopedic inpatient's overall health and may lead to better outcomes.

An integrated approach by undertaking the factors responsible for depression in-depth would ensure the reduction in length of ortho-illness and hospitalization associated to orthopedic trauma and a more effective way of rehabilitation and promotion of orthopedic sciences.

\section{CONCLUSIONS}

Higher incidence of depressive disorder recorded in female was significantly different from male. Prevention and treatment require more clinical and research attention to reduce the public health burden of depression among orthopedic inpatients. The understanding of the nature and causes of depression has evolved over the centuries, though this understanding is incomplete and has left many aspects of depression as the subject of discussion and research. The results suggest that higher depressive disorder does occur in indoor orthopaedic patients that associated with various clinical and demographical variables. This study has highlighted that depressive disorder was disabling factor in better functional recovery and frequent in female after orthopedic trauma.

\section{Implications of the study}

Depression is probably very common in orthopedic inpatients and has significant effects on important functional outcomes. An early detection of depressive disorder followed by and adequate intervention based on psychological support can provide good results and better functional recovery. Authors strongly support the introduction of a routinely determination of depressive disorder for admitted indoor orthopedic patients in order to begin as soon as possible an adequate treatment.

Moreover, the study evaluated a relationship between presences of depression associated with functional outcomes responsible for better recovery after orthopedic injury and therefore awareness among medical professional regarding the depressive disorder among orthopedic inpatients may be created.

\section{REFERENCES}

1. Sandra S. Depression: Questions You Have-Answers You Need. People's Medical Society 1997. ISBN 978-1-882606-14-6.

2. Sharma BK and Wavare R. Academic stress due to depression among Medical and Para-medical students in an Indian medical college: Health initiatives cross sectional study. Journal of Health Sciences 2013;3(5):29-38.

3. Moussavi S, Chatterji S, Verdes E, Tandon A, Patel V and Ustun B. Depression, chronic diseases, and decrements in health: results from the World Health Surveys. Lancet 2007; 370:851-858.

4. Kessler RC, McGonagle KA, Zhao S, Nelson CB, Hughes M, Eshleman $S$ et al. Lifetime and 12-month prevalence of DSMIII-R psychiatric disorders in the United States. Results from the National Comorbidity Survey. Archives of General Psychiatry 1994,51:8-19.

5. Lépine JP, Gastpar M, Mendlewicz J and Tylee A. Depression in the community: The first pan-European study DEPRES (Depression Research in European Society). International Clinical Psychopharmacology 1997;12:19-29.

6. McCarthy ML, MacKenzie EJ, Edwin D, Bosse MJ, Castillo RC and Starr A. LEAP study group. Psychological distress associated with severe lower-limb injury. Journal of Bone and Joint Surgery 2003;85:1689-1697.

7. Holbrook TL, Anderson JP, Sieber WJ, Browner D and Hoyt DB Outcome after major trauma: discharge and 6-month follow-up results from the Trauma Recovery Project. Journal of Trauma 1998;45:315-323.

8. Mayou R, Bryant B and Duthie R. Psychiatric consequences of road traffic accidents. British Medical Journal 1993;307:647-651.

9. Crichlow RJ, Andres PL, Morrison SM, Haley SM and Vrahas MS. Depression in orthopaedic trauma patients: Prevalence and severity. Journal of Bone and Joint Surgery. American volume 2006;88(9):1927-33.

10. Holbrook TL, Anderson JP, Sieber WJ, Browner D and Hoyt DB. Outcome after major trauma: 12-month and 18-month follow-up results from the Trauma Recovery Project. Journal of Trauma 1999, 46:765-771.

11. Ponzer S, Bergman B, Brismar B and Johansson LM. A study of patient-related characteristics and outcome after moderate injury. Injury 1996;27:549-555.

12. Brunsvold GL, Oepen G, Federman EJ and Akins R. Comorbid depression and ADHD in children and adolescents. Psychiatric Times 2008;25(10).

13. Powers PS, Santana CA. Surgery. In: Levenson JL, ed. Essentials of Psychosomatic Medicine. Washington, DC: American Psychiatric Publishing 2007:261-284.

14. Powers PS, Santana CA. Surgery. In: Levenson JL, ed. The American Psychiatric Publishing Textbook of Psychosomatic Medicine. Washington, DC: American Psychiatric Publishing 2005:647-674.

15. Shalev AY, Freedman S, Perry T, Brandes D, Sahar T and Orr SP et al. Prospective study of posttraumatic stress disorder and depression following trauma. American Journal of Psychiatry 1998;155(5):630-637.

16. Husain N, Chaudhry I, Afsar S and Creed F.Psychological distress among patients attending a general medical outpatient clinic in Pakistan. General Hospital Psychiatry 2004;26(4):277-281. 
17. Nickinson RS, Board TN and Kay PR. Post-operative anxiety and depression levels in orthopaedic surgery: a study of 56 patients undergoing hip or knee arthroplasty. Journal of Evaluation in Clinical Practice 2009;15(2):307-310.

18. Mont D. Measuring health and disability. Lancet 2007;369:16581663.

19. Sublette ME, Ellis SP, Geant AL and Mann JJ Metaanalysis of the effects of eicosapentaenoic acid (EPA) in clinical trials in depression. Journal of Clinical Psychiatry 2011;72(12):1577-84.

20. McCarthy ML, MacKenzie EJ, Edwin D, Bosse MJ, Castillo RC and Starr A. LEAP study group. Psychological distress associated with severe lower-limb injury. Journal of Bone and Joint Surgery. American volume 2003;85:1689-1697.

21. Bjørn Hildrum, Ulla Romild and Jostein Holmen. Anxiety and depression lowers blood pressure: 22-year follow-up of the population based HUNT study, Norway. BMC Public Health. 2011:11.

22. Zung WWK. Self rating depression scale. Archeives of General Psychiatry 1965;12:63-70.

23. Sherina MS, Rampal, L, Hanim MA and Thong P L. The prevalence of depression among elderly warded in a tertiary care centre in Wilayah Persekutuan. Medical Journal of Malaysia 2006;61(1):15-21.

24. Husain N, Humail SM, Chaudhry IB, Rahman R, Robinson H and Creed F. Psychological distress among patients of an orthopaedic outpatient clinic: a study from a low-income country. Annals of General Psychiatry 2010;9:9.

25. Levenson JL. Psychiatric Issues in Surgical Patients Part I: General Issues. Primary Psychiatry 2007;14(5):35-39

26. Nota SP, Bot AG, Ring D and Kloen P. Disability and depression after orthopaedic trauma. Injury 2014;pii: S0020-1383(14)003052. Epub ahead of print.

27. Iolascon G, Cervone M, Gimigliano R, Pietro GD and Gimigliano F. Neuropsychiatric disorders in hip fracture. Clinical Cases in mineral and bone metabolism 2011;8(3):49-53.

28. Gureje O. Depression and disability: comparisons with common physical conditions in the ibadan study of ageing. Journal of the American Geriatrics Society 2008;56(11):2033-2038.

29. Sharma BK, Wavare R, Deshpande A, Nigam $R$ and Chandorkar R. A study of academic stress and its effect on vital parameters in final year medical students at SAIMS Medical College, Indore, Madhya Pradesh. Biomedical Research 2011;22(3):361-365.

30. Holmes $\mathrm{J}$ and House A. Psychiatric illness predicts poor outcome after surgery for hip fracture: a prospective cohart study. Psychological Medicine 2000;30(4):921-929.

31. Ponsford J, Hill B, Karamitsios M and Bahar-Fuchs A. Factors influencing outcome after orthopedic trauma. Journal of Trauma 2008;64(4):1001-1009.

\section{Authors Contribution:}

RKJ: Concept and design of the study, reviewed the literature, manuscript preparation and critical revision of the manuscript. RR: Concept, collected data and review of literature and helped in preparing first draft of manuscript. BKS: Conceptualized study, literature search, statistically analyzed and interpreted, prepared first draft of manuscript and critical revision of the manuscript. VK: Concept of study, collected data and review of study.

Source of Support: Nil, Conflict of Interest: None declared. 